\section{Beyond the cellulose: Oxygen isotope composition of plant lipids as a proxy for terrestrial water balance}

\section{L.C.R. Silva ${ }^{1 *}$, G. Pedroso ${ }^{1,2}$, T.A. Doane ${ }^{1}$,} F.N.D. Mukome', W.R. Horwath

\begin{abstract}
doi: 10.7185/geochemlet.1504

There is growing interest in using stable isotopes to measure the impact of shifting water regimes on terrestrial ecosystems. The analysis of oxygen isotopes $\left(\delta^{18} \mathrm{O}\right)$ of plant cellulose has been widely used for that purpose, but its application is limited by cellulose's short life in most soils and sediments. Here we compare $\delta^{18} \mathrm{O}$ values of cellulose and plant lipids (hexaneextractable compounds) to assess the value of bulk lipids as a proxy for water balance. Using a set of field experiments with three $C_{3}$ and three $C_{4}$ species, we found significant differences in ${ }^{18} \mathrm{O}$ enrichment in response to irrigation regime, with a strong linear relationship observed between cellulose and lipid signals. Imposed drought increased lipid $\delta^{18} \mathrm{O}$ values of all species relative to controls and also affected the carbon isotope composition $\left(\delta^{13} \mathrm{C}\right)$ of cellulose, reflecting increased water-use efficiency in $C_{3}$ plants. Lipid extracts did not differ with respect to $\delta^{13} \mathrm{C}$ values, but $\delta^{18} \mathrm{O}$ signals consistently reflected drought effects in $\mathrm{C}_{3}$ and $\mathrm{C}_{4}$ species, regardless of variation in productivity and abundance of oxygen-containing functional groups. These results show that oxygen isotope composition of plant lipids can be used as a proxy for changing water regimes.
\end{abstract}

Received 7 February 2015 | Accepted 24 March 2015 | Published 22 April 2015

\section{Introduction}

The study of shifting water regimes and their impact on the terrestrial ecosystems is a research frontier in which quantitative metrics are still being established. The need to characterise climate variability and to measure the impact of drought on natural and managed ecosystems has led to increasing interest in stable isotope proxies (Silva and Anand, 2013; Maxwell et al., 2014; Silva, 2014). The oxygen isotope composition $\left(\delta^{18} \mathrm{O}\right)$ of plant cellulose provides an integrated measure

1. Department of Land, Air and Water Resources, University of California, Davis, 95616 CA, USA
Corresponding author (email: Icsilva@ucdavis.edu)

2. Department of Soil Sciences, Universidade Federal Rio Grande do Sul, 91540 RS, Brazil of the balance between water inputs (precipitation and/or irrigation) and losses through evapotranspiration (ET), and has been used to examine the effects of climatic variability on terrestrial systems (Kahmen et al., 2011; Sternberg, 2009). Although extensively used in living plants (e.g., tree rings), the analysis of cellulose is limited by its typically short life after decomposition of plant biomass. Under particular conditions, cellulose extracted from fossil plants have been used to produce climate records that go back millions of years (Jahren and Sternberg, 2003), but such well-preserved samples are rare. In contrast to cellulose, plantderived lipids can persist in soils and sediments due to their low biodegradability and stabilisation into hydrophobic domains of organic matter (Matsumoto et al., 2007; Assis et al., 2011), providing a potential long-term record of terrestrial water balance.

Plant lipids may be broadly defined as hydrophobic or amphiphilic molecules originating entirely or in part from two types of biochemical subunits, ketoacyl and isoprene groups, which are building blocks for molecules of various structures and polarities, including some with no oxygen at all (e.g., alkanes in leaf surface wax) and others that carry various amount of oxygen (Fahy et al., 2009). The value of lipid hydrogen isotope analysis $\left(\delta^{2} \mathrm{H}\right)$ has already been recognised for specific compounds recovered from soils and sediments (Sachse et al., 2012) The study of lipid $\delta^{18} \mathrm{O}$ signals has the potential to improve $\delta^{2} \mathrm{H}$ records by, for example, allowing water loss to be partitioned into evaporation and transpiration (Voelker et al., 2014).

The first step towards the use of lipid $\delta^{18} \mathrm{O}$ records is to demonstrate that a signal related to changes in water balance is recorded in such compounds. The second step is then to demonstrate that this signal is preserved in soils and sediments. The present study is concerned with the first step. However, without losing sight of the second step, we imposed the restriction that lipid extracts should contain only the most apolar compounds present in the plant biomass, under the assumption that these are also the most likely to persist after deposition (Matsumoto et al., 2007). To advance the interpretation of lipid $\delta^{18} \mathrm{O}$ signals, we compared measurements of cellulose and hexane-extractable compounds of $C_{3}$ and $C_{4}$ species, grown under contrasting water regimes in replicated field experiments. In addition, we analysed the carbon isotope composition $\left(\delta^{13} \mathrm{C}\right)$ of cellulose and lipids as a way to assess plant water-use efficiency (Farquhar and Von Caemmerer, 1982). Alongside these isotopic measurements, we used spectroscopic analyses to qualitatively describe the molecular composition of lipid extracts and all results are integrated into a consideration of potential applications in ancient and contemporary settings.

\section{Methods}

Field Experiment. The field experiment was conducted at the University of California Five Points Experimental Station (36 $20^{\prime} 10.28^{\prime \prime} \mathrm{N}, 120^{\circ} 6^{\prime} 38.40^{\prime \prime} \mathrm{W}$ ). This site experiences hot summers, cool and dry winters, and average annual 
precipitation of $173 \mathrm{~mm}$. Plots of $27 \mathrm{~m}^{2}$ were established under homogeneous edaphic conditions (Tables S-1 and S-2) in which three $C_{3}$ and three $C_{4}$ species were grown (Table 1). Following a complete randomised block design with four field replications, monocultures of each species were established using sprinkler irrigation (2008), later converted to flood irrigation (2009), after which two irrigation treatments were imposed through 2011. Daily potential ET was obtained from the on-site meteorological station and multiplied by species-specific coefficients (Allen and Pruitt, 1991). The amount of water to be applied was determined based on $100 \%$ or $70 \%$ of the potential ET, representing full water loss replenishment and deficit irrigation (imposed drought) treatments, respectively. Plots were irrigated when the accumulated ET reached $150 \mathrm{~mm}$, for an average of 11 irrigation events per year. Precipitation water was factored into the calculation for irrigation. The average annual $\delta^{18} \mathrm{O}$ of the precipitation is about -7.8\%o. Irrigation water was a combination of aqueduct source (originating in the Sacramento-San Joaquin Delta region) and a groundwater well at a depth of 150-180 metres. The same irrigation water was used in all plots throughout the experiment.

Table 1 Species description.
\begin{tabular}{|l|l|l|l|}
\hline \multicolumn{1}{|c|}{ Common name } & \multicolumn{1}{|c|}{ Scientific name } & \multicolumn{1}{c|}{ Variety } & \multicolumn{1}{c|}{ Metabolism } \\
\hline Miscanthus & Miscanthus giganteus & Hybrid giganteus & Warm-season $C_{4}$ \\
\hline Switchgrass & Panicum virgatum & Alamo & Warm-season $C_{4}$ \\
\hline Bermuda grass & Cynodon dactylon & Giant NK 37 & Warm-season $C_{4}$ \\
\hline Alfalfa & Medicago sativa & Big Kaw & Warm-season $C_{3}$ \\
\hline Tall Fescue & Festuca arundinacea & Fawn & Cool-season $C_{3}$ \\
\hline Tall wheatgrass & Agropyron elongatum & Jose & Cool-season $C_{3}$ \\
\hline
\end{tabular}

Sampling and analysis. At the end of the experiment, the aboveground biomass of all plots was harvested and ground to $<0.5 \mathrm{~mm}$ for analysis. Pure alpha cellulose was isolated (Brendel et al., 2000) and the lipid fraction was obtained by Soxhlet extraction with hexane for 10 hours. Although less efficient at extracting total lipids, as compared to more polar solvent mixtures (e.g., chloroform:methanol), hexane was chosen to minimise extraction of transient polar lipids such as phospholipids and degradation products of chlorophyll.

The isotopic composition of oxygen was determined using an Elementar PyroCube (Elementar Analysensysteme, Hanau, Germany) interfaced to a PDZ Europa 20-20 IRMS (Sercon Ltd., Cheshire, UK). Three analytical replicates were used for each plot and working standards of cellulose and hexadecyl palmitate were interspersed throughout each run to determine analytical precision. Carbon isotopic composition of cellulose and lipids was determined using a PDZ Europa ANCA-GSL elemental analyser interfaced to a PDZ Europa 20-20 IRMS (Sercon Ltd., Cheshire, UK). A certified analytical standard of known $\delta^{13} \mathrm{C}$ was used to confirm accuracy and precision. Data are expressed as $\delta^{18} \mathrm{O}$ and $\delta^{13} \mathrm{C}(\%)$ relative to Vienna Standard Mean Ocean Water (VSMOW) and Pee Dee Belemnite (VPDB), respectively.

Elemental analysis of hexane-extracted material showed an oxygen content of $6-11 \%$ and a carbon content of $71-79 \%(w / w)$. Fourier Transform Infrared Spectroscopy (FTIR) was used to describe the molecular composition of hexane extracts, focusing on oxygen-containing groups. Samples were analysed using attenuated total reflectance (ATR) FTIR. The spectra were collected on a Thermo Nicolet 6700 spectrophotometer (Thermo Scientific, Madison, WI) with a diamond single bounce accessory (GladiATR, PIKE Technologies). After collection, the spectra were normalised to the aliphatic $\mathrm{C}-\mathrm{H}$ peak at approximately $2913 \mathrm{~cm}^{-1}$ prior to performing spectral subtraction. All FTIR spectra were collected in triplicate using $4 \mathrm{~cm}^{-1}$ resolution and $1.2 \mathrm{kHz}$ scanning speed for a total of 128 co-added scans per analysis (Parikh et al., 2014).

Statistical analysis. Average differences in isotopic composition were compared using paired t-tests. When appropriate, least-square regressions were performed to evaluate the relationship between cellulose and lipid isotopic ratios. Average data points and standard deviations were plotted for each species, blocked by water balance treatment, incorporating 4 field replicates each. Molecular characterisation of lipids was performed separately for each species and treatment.

\section{Results and Discussion}

Isotopic composition of cellulose and lipids. Irrigation treatments caused clear changes in lipid and cellulose $\delta^{18} \mathrm{O}$ values. Despite significant differences among species, plants growing under drought $\left(70 \%\right.$ ET) were always enriched in ${ }^{18} \mathrm{O}$ relative to plants growing under full ET replenishment (Fig. 1a). In cellulose, ${ }^{18} \mathrm{O}$ enrichment in response to drought was clearer in $C_{3}\left(>1 \%\right.$ ) compared to $C_{4}$ $(\sim 0.5 \%$ o) plants, while in lipids, consistent responses were observed $(\sim 0.75 \%$ o $)$ with no statistical difference between $C_{3}$ and $C_{4}$ plants. We found a strong linear relationship between cellulose and lipid $\delta^{18} \mathrm{O}$ values $(\mathrm{P}<0.01)$, reflecting consistent responses across species (Fig. 1b).

The effect of drought was also evident in cellulose $\delta^{13} \mathrm{C}$, reflecting expected differences between plant metabolism (Pearcy and Ehleringer, 1984), and showing a clear separation in response to water balance treatments in $\mathrm{C}_{3}$ plants (Fig. 1c). This separation confirms an anticipated increase in water-use efficiency under drought, which was surprisingly not apparent in lipid $\delta^{13} \mathrm{C}$ values, and may be explained by the heterogeneous composition of lipid extracts (discussed below). While ${ }^{13} \mathrm{C}$ fractionation in $\mathrm{C}_{3}$ plants is controlled by the stomata-regulated ratio of intercellular to ambient $\mathrm{CO}_{2}$ concentrations $\left(\mathrm{c}_{\mathrm{i}} / \mathrm{c}_{\mathrm{a}}\right)$, variation in $\mathrm{C}_{4}$ bundle-sheath leakiness can either dampen or amplify the effects of $\mathrm{c}_{\mathrm{i}} / \mathrm{c}_{\mathrm{a}}$, so that $\delta^{13} \mathrm{C}$ measurements cannot be used to assess water-use efficiency in $\mathrm{C}_{4}$ plants (Cernusak et al., 
2013). Nevertheless, we found ${ }^{18} \mathrm{O}$ enrichment of similar magnitude and direction in $\mathrm{C}_{3}$ and $\mathrm{C}_{4}$ lipids under drought, demonstrating the value of $\delta^{18} \mathrm{O}$ measurements as a general proxy for water balance.
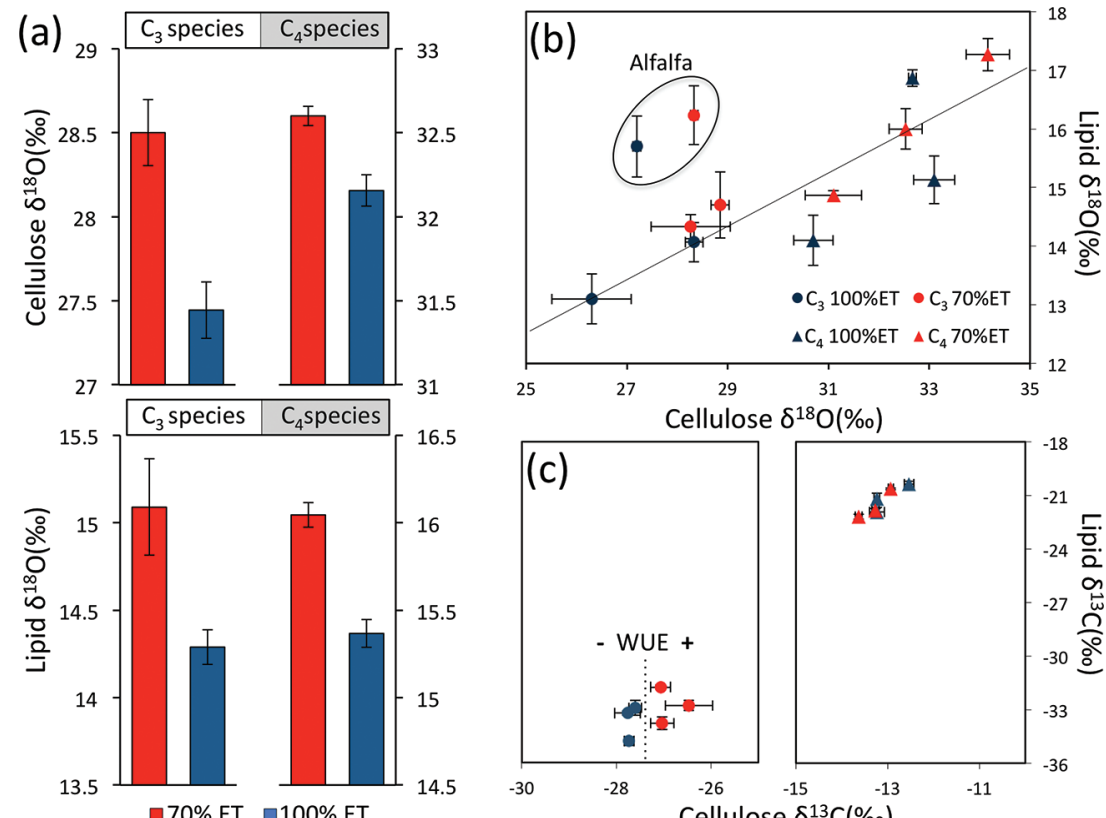

igure 1 (a) Average $\delta^{18} \mathrm{O}$ values of $C_{3}$ and $C_{4}$ species under full evapotranspiration replenishment $(100 \% \mathrm{ET})$ and deficit irrigation $(70 \% \mathrm{ET})$. Differences between treatments were significant (t-test; $\mathrm{P}<0.01$ ) in all cases. (b) Relationship between cellulose and lipid $\delta^{18} \mathrm{O}$ value excluding alfalfa: $y=0.4449 x+1.4277 ; R^{2}=0.76(P<0.01)$. (C) Cellulose and lipid 8 (t) $C$ values; significant differences were observed in cellulose of $C_{3}$ species (t-test; $P<0.01$ ), but not in

Interpreting differences in isotopic composition. Leaf and xylem water are both sources of oxygen incorporated into organic compounds during biosynthesis, but each of these sources contributes a distinct isotopic signal (Sternberg, 2009). Reductions in plant water supply are expected to increases the contribution of isotopically enriched leaf water, while decreasing the flux of relatively unenriched xylem water to the leaf (Ogée et al., 2007). This process is influenced by the distribution of leaf veins, which caused the greatest ${ }^{18} \mathrm{O}$ enrichment in lipids relative to cellulose in alfalfa, the only dicot species. This observation is consistent with previous work on leaf $\delta^{2} \mathrm{H}$ values showing significant differences in ${ }^{2} \mathrm{H}$ enrichment of the $n-\mathrm{C}_{29}$ alkane biomarker among plant growth forms, in which dicot species were the most and graminoids the least enriched in ${ }^{2} \mathrm{H}$, respectively (Sachse et al., 2012).
Fatty acid transfer reactions within the plastid yield a significant reduction in ${ }^{18} \mathrm{O}$ content of water in relation to the cytosol (Pollard and Ohlrogge 1999) contributing to differences between the isotopic composition of lipids and cellulose. It is important to note that lipids contain far less oxygen than cellulose and do not undergo the postsynthetic isotopic exchange that happens during the hydration of carbonyl groups of the intermediates of cellulose synthesis (Sternberg and DeNiro, 1983). Therefore, intrinsic species traits and biosynthetic differences explain the offset between lipid and cellulose $\delta^{18} \mathrm{O}$ values across species (Fig. 1b).

Our observations show that the balance between water input and evapotranspiration can be directly interpreted from lipid oxygen isotopes in monocultures of $\mathrm{C}_{3}$ and $\mathrm{C}_{4}$ species, providing a powerful tool for selecting traits that would optimise water-use efficiency under field conditions. However, the large variation in ${ }^{18} \mathrm{O}$ enrichment between species indicates that the effect of a diverse vegetation cover could confound water balance signals. Therefore, analyses of lipids in natural ecosystems are more likely to successfully reconstruct climate variability where vegetation composition is known to be stable. This could be accomplished by appropriate evaluation of vegetation composition in contemporary settings, and palaeoecological reconstructions in ancient settings based on companion proxies for vegetation change (e.g., fossil pollen and $\delta^{13} \mathrm{C}$ of organic matter; Silva and Anand, 2013; Silva, 2014).

Characterisation of lipid extracts. The FTIR spectra of lipid extracts show that substantial differences in molecular composition exist among species and in response to growing conditions. The difference spectra (Fig. 2), obtained by subtracting results of water-limited from non-limited fields, show that all common oxygen-containing functional groups found in lipids are more abundant under drought. These groups include long-chain aliphatic esters, ketones, carboxylic acids, ethers, alcohols, as well as aromatic compounds (Table S-3 and Fig. S-1). This observation is consistent with general variations in plant lipid composition (Fahy et al., 2009), as drought stress tends to decrease the abundance of more polar lipids (e.g., phospholipids) while increasing the relative abundance of nonpolar compounds (Harwood, 1998).

Since the 1970s, when the use of $\delta^{18} \mathrm{O}$ values obtained from tree rings was first established, cellulose $\delta^{18} \mathrm{O}$ records have been used as a proxy for drough stress. Classic conceptual models (Scheidegger et al., 2000) have coupled $\delta^{18} \mathrm{O}$ and $\delta^{13} \mathrm{C}$ values to distinguish differences in stomatal response from photosynthetic capacity. In the present dataset, this link was apparent in cellulose but not in lipids, probably due to the heterogeneity of bulk lipid extracts. Nevertheless, lipid extracts of $C_{3}$ and $C_{4}$ plants showed clear isotopic signals in response to drought. This result demonstrates that $\delta^{18} \mathrm{O}$ values of bulk plant lipids serve as a more general proxy for water balance than $\delta^{13} \mathrm{C}$ records, which are limited to $\mathrm{C}_{3}$ plants and therefore necessarily exclude many important crops and tropical ecosystems. This is particularly important because shifts in $\delta^{18} \mathrm{O}$ signals in response to treatments were independent of variation in plant productivity (Fig. $\mathrm{S}-2$ ) and large interspecific differences in molecular composition in response to drought (Fig. S-1) 
The value of a new lipid proxy. The present study provides empirical evidence to support the use of lipid oxygen isotopic composition as a proxy for water balance in contemporary settings, which also has the potential to improve reconstructions of past climates. Measurements of hydrogen isotopes in plant lipids preserved in soils and sediments have been previously used to reconstruct

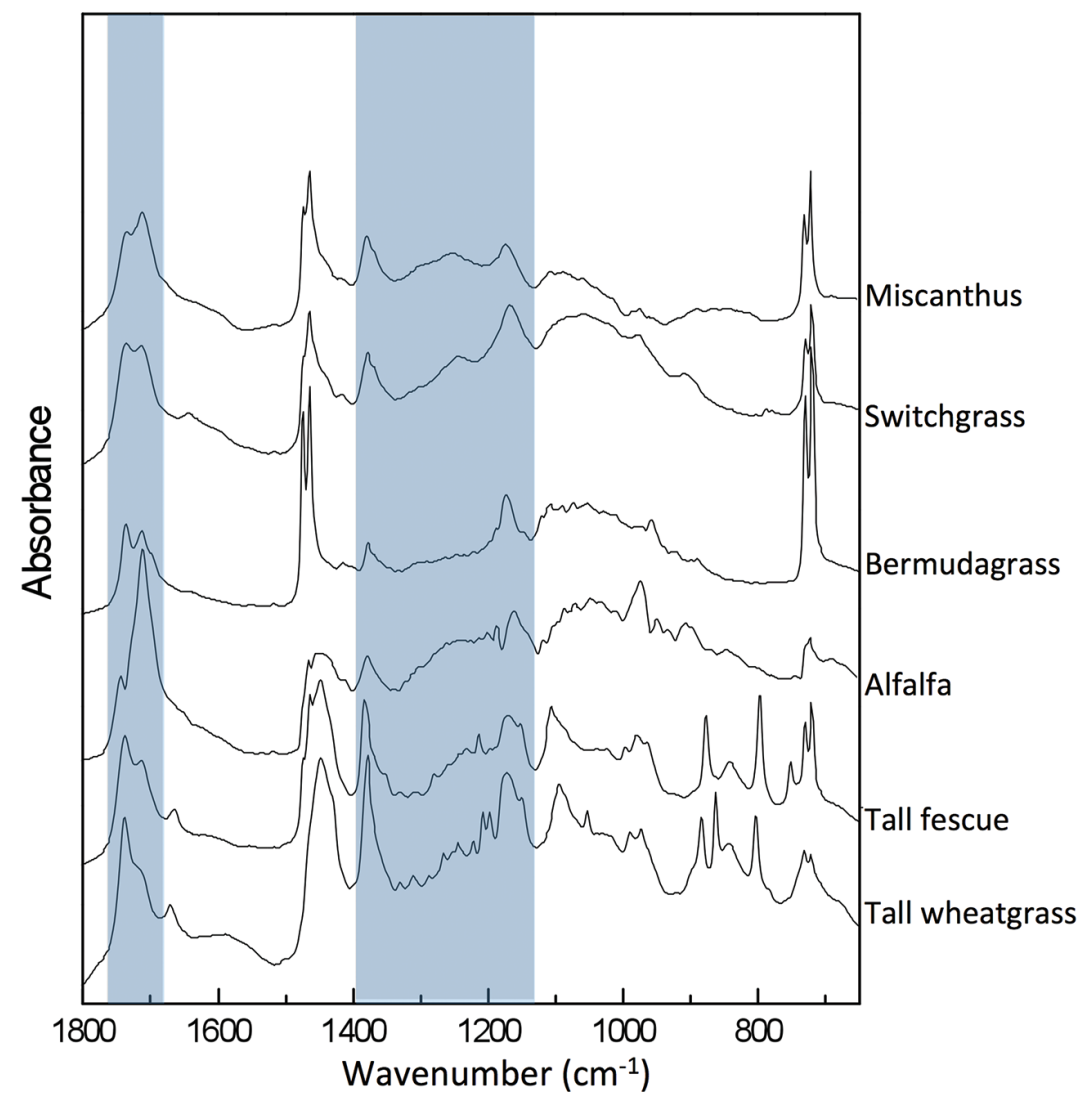

Figure 2 Difference spectra obtained by subtracting the spectra of lipid extracts of plants growing under deficit irrigation (70\% ET) from those growing under full water replenishment. Highlighted areas correspond to oxygen-containing groups (e.g., vibration from aromatic C-O, esters and ketones). The spectra have been shifted vertically for clarity. A complete spectral characterisation is presented in Table S-3 and Figure S-1.

climate variability, but these isotopic signals are sensitive to biochemical, physiological, and environmental influences (Sachse et al., 2012), which can be better constrained by dual isotope analyses (Scheidegger et al., 2000; Maxwell et al. 2014; Voelker et al., 2014). The much lower abundance of oxygen relative to hydrogen atoms in plant lipids has so far limited the production of $\delta^{18} \mathrm{O}$ records from specific compounds. However, persistent oxygen-containing lipids, such as long-chain $n$-alkanoic acids, are commonly recovered in sedimentary profiles and analysed for $\delta^{2} \mathrm{H}$ (Feakins et al., 2007), and could lead to water balance reconstructions with improved precision. In the case of hydrogen, the key to success has been the study of specific compounds in which the effects of hydrological shifts and biosynthesis can be isolated. Similarly, the analysis of oxygen isotopes of hemicellulose degradation products in soil has been recently shown to reflect the balance between precipitation and evapotranspiration across broad latitudinal gradients (Tuthorn et al., 2014; Zech et al., 2014). We expect bulk lipid samples to serve as a basis from which compound-specific oxygen and hydrogen records can be developed to better understand present and decipher past impacts of climatic change on terrestrial systems.

\section{Acknowledgements}

We thank Johan Six, Bruce Linquist and Chris Van Kessel for logistic support in conducting the field experiments; Sanjai Parikh for laboratory facilities and equipment necessary for the infrared spectral analysis; Leonel Sternberg and participants of the Goldschmidt Conference 2014, session on Plant Compounds as Ecohydrological Tracers, for valuable discussion. This work is supported by the California Department of Food and Agriculture Project \#26491 (LS), by the NSF-NIFA Water Sustainability and Climate Program \#2014-67003-22077 (WH; LS), and the J.G. Boswell Endowed Chair in Soil Science.

Editor: Liane G. Benning

\section{Additional Information}

Supplementary Information accompanies this letter at http://www. geochemicalperspectivesletters.org/article1504

Reprints and permission information is available online at http://www. geochemicalperspectivesletters.org/copyright-and-permissions

Cite this letter as: Silva, L.C.R., Pedroso, G., Doane, T.A., Mukome, F.N.D., Horwath, W.R. (2015) Beyond the cellulose: Oxygen isotope composition of plant lipids as a proxy for terrestrial water balance. Geochem. Persp. Let. 1, 33-42.

\section{References}

AlleN, R.G., PruitT, W.O. (1991) FAO-24 Reference Evapotranspiration Factors. Journal of Irrigation and Drainage Engineering 117, 758-773. 
Assis, C.P., GonzÁlez-VILA, F.J., Jucksch, I., GonZÁlez-Pérez, J.A., Neves, J.C.L., LANI, J.L., Mendonç̧, E.S. (2011) Lipid abundance and composition of a humic Oxisol as a function of land use E.S. (2011) Lipid abundance
Scientia Agricola $68,230-236$.

BRendel, O., IANNETTA, P.P.M., STewart, D. (2000) A rapid and simple method to isolate pure alphacellulose. Phytochemical Analysis 11, 7-10.

Cernusak, L.A., Ubierna, N., Winter, K., Holtum, J.A.M., Marshall, J.D., Farquhar, G.D. (2013) Environmental and physiological determinants of carbon isotope discrimination in terrestrial plants. The New Phytologist 200, 950-965.

Fahy, E., Subramaniam, S., Murphy, R.C., Nishijima, M., Raetz, C.R.H., Shimizu, T., Spener, F., van MeER, G., WAKELAM, M.J.O., DenNIS, E.A. (2009) Update of the LIPID MAPS comprehensive classification system for lipids. Journal of Lipid Research 50, S9-S14.

FARQuHAR, G.D., Von CAEMmerer, S. (1982) Modelling of photosynthetic response to environmental conditions. In: Lange, O.L., Nobel, P.S., Osmond, C.B., Ziegler, H. (Eds.) Encyclopedia of Plant Physiology 549-587.

FEAKINS, S.J., EGLINTON, T.I., DE MENOCAL, P.B. (2007) A comparison of biomarker records of northeast African vegetation from lacustrine and marine sediments (ca. 3.40 Ma). Organic Geochemistry 38, 1607-1624.

HARWOOD, J. (1998) Plant Lipid Biosynthesis: Fundamentals and Agricultural Applications. Society for Experimental Biology, Seminar Series 67, Cambridge University Press, 378 pp.

Jahren, A.H., SternberG, L.S.L. (2003) Humidity estimate for the middle Eocene Arctic rain forest. Geology 31, 463-466.

Kahmen, A., SAchse, D., ARndt, S.K., Tu, K.P., FARrington, H., Vitousek, P.M., Dawson, T.E. (2011) Cellulose $\delta^{18} \mathrm{O}$ is an index of leaf-to-air vapor pressure difference (VPD) in tropical plants.

Matsumoto, K., KaWAmURA, K., Uchida, M., Shibata, Y. (2007) Radiocarbon content and stable carbon isotopic ratios of individual fatty acids in subsurface soil: Implication for selective microbial isotopic ratios of individual fatty acids in subsurface soil: Implication for selective m
degradation and modification of soil organic matter. Geochemical Journal 41, 483-492.

Maxwell, T., Silva, L.C.R., HoRWath, W.R. (2014) Using multielement isotopic analysis to decipher drought impacts and adaptive management in ancient agricultural systems. Proceedings of the National Academy of Sciences of the United States of America 111, E4807-E4808.

OgéE, J., CuntZ, M., Peylin, P., BARIAC, T. (2007) Non-steady-state, non-uniform transpiration rate and leaf anatomy effects on the progressive stable isotope enrichment of leaf water along monoco leaves. Plant, Cell and Environment 30, 367-387.

PARIKH, S. J., MuKome, F.N.D., Zhang, X. (2014) ATR-FTIR spectroscopic evidence for biomolecular phosphorus and carboxyl groups facilitating bacterial adhesion to iron oxides. Colloids and Surfaces Biointerfaces 119, 38-46.

PearCY, R.W., EhLeRInger, J. (1984) Comparative ecophysiology of C3 and C4 plants. Plant, Cell and Environment 7, 1-13.

Pollard, M., OHLrogGe, J. (1999) Testing models of fatty acid transfer and lipid synthesis in spinach leaf using in vivo oxygen-18 labeling. Plant Physiology 121, 1217-1226.

Sachse, D., Billault, I., Bowen G.J., Chikaraishi, Y., Dawson, T.E., Feakins, S.J., Freeman, K.H., Magill, C.R., McInerney, F.A., van Der MeEr, M.T.J., Polissar, P., Robins, R.J., SACHS, J.P., SCHMDI, H. L., SEssioNs, A.L., WHIT, J.W.C., WEST, J.B., KAHMEN, A. (2012) Molecular paleohydrology: interpreting the hydrogen-isotopic composition of lipid bionarkers from photosyn-

SCHeIDEgGer, Y., SAURER, M., BAHN, M., SieGWOLF, R. (2000) Linking stable oxygen and carbon isotopes with stomatal conductance and photosynthetic capacity: a conceptual model. Oecologia 125, $350-357$.

SiLVA, L.C.R., ANAND, M. (2013) Historical links and new frontiers in the study of forest-atmosphere interactions. Community Ecology 14, 208-218.
SILVA, L.C.R. (2014) Importance of climate-driven forest-savanna biome shifts in anthropological and ecological research. Proceedings of the National Academy of Sciences of the United States of America 111, E3831-E3832.

STERNBERG L. (2009) Oxygen stable isotope ratios of tree-ring cellulose: the next phase of understanding. New Phytologist 181, 553-562

SternberG, L., DeNiro, M.J.D. (1983) Biogeochemical implications of the isotopic equilibrium fractionation factor between the oxygen atoms of acetone and water. Geochimica et Cosmochimica Acta 47, 2271-2274.

Tuthorn, M., Zech, M., Ruppenthal, M., Oelmann, Y., Kahmen, A., Del Valle, H.F., Wilcke, W GLASER, B. (2014) Oxygen isotope ratios $\left({ }^{18} \mathrm{O} /{ }^{16} \mathrm{O}\right)$ of hemicellulose-derived sugar biomarkers in plants, soils and sediments as paleoclimate proxy II: Insight from a climate transect study. Geochimica et Cosmochimica Acta 126, 624-634.

Voelker, S., Brooks, J., Meinzer, F., Roden, J., Pazdur, A., Pawelczyk, S., Hartsough, P., Snyder, K, PLAVCOVÁ, L., ŠANTRŮ̌̌EK, J. (2014) Reconstructing relative humidity from plant $\delta^{18} \mathrm{O}$ and $\delta \mathrm{D}$ as deuterium deviations from the global meteoric water line. Ecological Applications 24, 960-975.

ZeCh, M., Mayr, C., Tuthorn, M., Leiber-SAuheitl, K., Glaser, B. (2014) Oxygen isotope ratios $\left({ }^{18} \mathrm{O} /{ }^{16} \mathrm{O}\right)$ of hemicellulose-derived sugar biomarkers in plants, soils and sediments as paleoclimate proxy I: Insight from a climate chamber experiment. Geochimica et Cosmochimica Acta 126, 614-623. 